\title{
Analisis Optimasi Citra Radiografi Pada Pemeriksaan Thorax Sistem Computed Radiography (CR) Terhadap Entrance Surface Dose (ESD)
}

\author{
Tri ambarsari ${ }^{1}$, Budi Santoso ${ }^{1}$, Nursama Heru Apriantoro², Febria Anita ${ }^{1}$. \\ ${ }^{1}$ Program Studi Fisika, Universitas Nasional, Sawo Manila, Pejaten, Pasar Minggu Jakarta \\ Selatan 12520 \\ ${ }^{2}$ Poltekkes Kemenkes Jakarta 2, Jakarta \\ Email : febria.anita85@gmail.com
}

\begin{abstract}
ABSTRAK. Telah dilakukan penelitian analisis variasi faktor eksposi pemeriksaan thorax terhadap dosis permukaan dan noise pada citra radiografi. Dilakukan 10 (sepuluh) kali ekspos pada phantom thorax dengan faktor eksposi $50 \mathrm{kV}-8 \mathrm{mAs}, 50 \mathrm{kV}-10 \mathrm{mAs}, 55 \mathrm{kV}$ $8 \mathrm{mAs}, 55 \mathrm{kV}-10 \mathrm{mAs}, 55 \mathrm{kV}-10 \mathrm{mAs}, 60 \mathrm{kV}-8 \mathrm{mAs}, 60 \mathrm{kV}-10 \mathrm{mAs}, 66 \mathrm{kV}-8 \mathrm{mAs}, 66$ $\mathrm{kV}-10 \mathrm{mAs}$ dan $102 \mathrm{kV}-1 \mathrm{mAs}, 102 \mathrm{kV}$ - 2,5 mAs untuk teknik kV tinggi. Untuk masingmasing faktor eksposi ditempelkan satu TLD yang diletakkan di tengah lapangan penyinaran untuk mengukur nilai dosis permukaan. Kondisi eksposi optimum pemeriksaan thorax PA (dinyatakan dengan nilai $\operatorname{lgM}$ ) terjadi ketika penggunaan faktor eksposi $55 \mathrm{kV}$ dengan 8 mAs karena nilai $\operatorname{lgM}$ yang didapat yaitu 1,91, nilai standar deviasi 6,605 dan nilai ESD sebesar 0,098 mGy.
\end{abstract}

Kata Kunci: Variasi faktor eksposi, Dosis permukaan, Computed Radiography (CR).

\begin{abstract}
This research has conducted about exposure factor variation analysis examination of the thorax surface dose and image noise in radiography. Do 10 (ten) times the exposure in the thorax phantom with various exposure factor such as $50 \mathrm{kV}-8 \mathrm{mAs}, 50$ $\mathrm{kV}-10 \mathrm{mAs}$, $55 \mathrm{kV}-8 \mathrm{mAs}$, $55 \mathrm{kV}-10 \mathrm{mAs}$, $55 \mathrm{kV}-10 \mathrm{mAs}$, $60 \mathrm{kV}-8 \mathrm{mAs}$, $60 \mathrm{kV}-10 \mathrm{mAs}$, 66 $\mathrm{kV}-8 \mathrm{mAs}$, $66 \mathrm{kV}-10 \mathrm{mAs}$, and $102 \mathrm{kV}-1 \mathrm{mAs}$, $102 \mathrm{kV}-2,5 \mathrm{mAs}$ for high $\mathrm{kV}$ technique. For each exposure factor the pinned, TLD placed in the middle of the field to measure the radiation dose level. The optimum exposure conditions of the thorax PA examination (expressed with IgM value) occurs when using exposure factor $55 \mathrm{kV}$ and $8 \mathrm{mAs}$ for IgM values obtained are 1.91, 6.605 for standard deviation values and ESD $0.098 \mathrm{mGy}$.
\end{abstract}

Keyword: Exposure factor, Entrance Surface Dose, Computed Radiography (CR). Reading list: 13 (2000 - 2014).

\section{PENDAHULUAN}

Salah satu pemeriksaan atau penyinaran sinar-X yang sering dan umumnya dilakukan pada pelayanan radiologi diagnostik adalah penyinaran sinar-X pada bagian dada (chest) atau yang biasa disebut dengan istilah pemeriksaan thorax. Namun pelayanan dengan pemanfaatan sinar$\mathrm{X}$ ini memiliki tingkat resiko yang tinggi meskipun kita tidak dapat merasakan atau melihatnya karena sinar-X merupakan radiasi pengion. Sinar-X dapat menimbulkan ionisasi yang selanjutnya membentuk radikal dalam jaringan tubuh yang dilewatinya. Efek radiasi terhadap manusia tersebut dapat muncul apabila tubuh manusia mendapatkan paparan radiasi dengan dosis yang melebihi ambang (efek deterministik) maupun dari akumulasi dosis yang dapat meningkatkan probabilitas timbulnya penyakit kanker (efek stokastik).

Untuk melindungi pasien dari efek akibat radiasi, keselamatan pasien pada setiap pemeriksaan sangat penting untuk diperhatikan. Dengan memperhatikan efek radiasi terhadap manusia yang mungkin terjadi. Sehingga penentuan nilai entrance surface dose (ESD) sangat penting untuk keselamatan pasien, karena berhubungan dengan resiko radiasi. Entrance Surface Dose (ESD) atau dosis entrans pasien dipengaruhi oleh berbagai faktor, antara lain teknik pemeriksaan, parameter eksposi, jumlah citra yang dibutuhkan dan karakteristik pasien. Oleh karena itu dosis pasien berbeda dari negara satu dengan negara yang lain, dari rumah sakit yang satu dengan rumah sakit yang lain, serta dari alat yang satu dengan alat yang lain. Sebaiknya setiap pemeriksaan tetap mengikuti konsep dasar yang diberikan oleh International Committee on 
Radiological Protection (ICRP) yaitu semua dosis radiasi harus diusahakan As Low as Reasonably Achievable (ALARA). Dengan makna dosis pasien diusahakan rendah, tetapi tidak sampai mengganggu tujuan untuk memperoleh diagnosa optimal yang diperlukan pasien.

Perkembangan peralatan medispun semakin maju seiring dengan kemajuan teknologi salah satunya adalah teknologi pencitraan yaitu berkembang dari reseptor citra film menjadi reseptor digital. Dengan berkembangnya teknologi maka rumah sakit pun banyak beralih menggunakan teknologi digital, baik itu Computed Radiography ataupun Digital Radiography. Pada penelitian ini akan dilakukan pengukuran entrance surface dose (ESD) untuk pemeriksaan radiografi thorax menggunakan phantom dengan menggunakan variasi faktor eksposi untuk mencari gambaran yang optimal menggunakan sistem pencitraan CR. Penelitian ini bertujuan untuk mengukur, membandingkan dan menganalisis hasil pengukuran ESD pada pemeriksaan thorax dan menilai hasil citra yang didapatkan dengan berbagai variasi faktor eksposi yang diberikan.

\section{BAHAN DAN METODE}

Entrance surface dose (ESD) merupakan salah satu kuantitas yang digunakan dalam radiodiagnostik untuk menyatakan dosis radiasi yang diterima objek, beberapa referensi menggunakan istilah lain yaitu entrance surface air kerma (ESAK). ESD merupakan dosis radiasi pada permukaan objek termasuk radiasi backscatter (hamburan balik) yang diukur pada pusat berkas radiasi di permukaan pasien atau phantom. Satuan lain yang sering digunakan adalah dosis serap (absorbed dose) dan dosis insiden (incident air kerma).

Perbedaan antara ESD dengan dosis insiden adalah bahwa ESD sudah termasuk dosis radiasi backscatter sementara dosis insiden tidak termasuk dosis radiasi backscatter sehingga ESD akan selalu lebih besar dari pada dosis insiden. Pengukuran ESD dapat dilakukan dengan cara langsung menggunakan pasien maupun tidak langsung dengan kalkulasi.Pengukuran ESD secara langsung dapat dilakukan dengan menggunakan TLD (Thermo Luminescent Detector) [1].

Keselamatan radiasi atau disebut juga proteksi radiasi merupakan cabang ilmu pengetahuan yang mempelajari masalah kesehatan manusia maupun lingkungan dan berkaitan dengan pemberian perlindungan kepada seseorang atau sekelompok orang atau kepada keturunannya terhadap kemungkinan negatif yang merugikan kesehatan akibat paparan radiasi ${ }^{[2]}$. Tujuan proteksi radiasi adalah untuk mencegah terjadinya efek non stokastik yang berbahaya, dan membatasi peluang terjadinya efek stokastik hingga pada nilai batas yang dapat diterima masyarakat serta untuk meyakinkan bahwa pekerjaan atau kegiatan yang menggunakan zat radioaktif atau sumber radiasi dapat dibenarkan. Prinsip proteksi radiasi adalah ALARA (As Low As Reasonably Achieveable), artinya semua penyinaran harus diusahakan serendahrendahnya karena sekecil apapun dosis radiasi efek stokastik tetap dapat timbul.

Dosimeter perorangan zat padat dibuat dari bahan kristal yang dapat menghasilkan efek tertentu ketika terkena paparan radiasi pengion. Ada berbagai jenis dosimeter perorangan zat padat yang saat ini banyak digunakan untuk keperluan rutin pemantauan dosis perorangan pekerja radiasi salah satunya dosimeter thermoluminesensi atau yang lebih dikenal dengan singkatan TLD (thermoluminensi dosimeter). Bahan hermoluminesensi dosimeter (TLD) adalah lithium flourida (LiF) dengan nomor atom efektifnya adalah 8,1 cukup ekivalen dengan nomor efektif jaringan tubuh manusia yang nilainya 7,4 [2]. Keuntungan dalam penggunaan alat ini adalah mudah dalam pengoperasiannya, evaluasi dapat dilakukan lebih cepat dari dosimeter lainnya, dapat memantau radiasi dengan rentang dosis dari rendah hingga tinggi, dapat dipakai ulang dan tidak peka terhadap faktor-faktor lingkungan. Proses pembacaan dosis perorangan dengan TLD dilakukan dengan cara membaca jumlah elektron yang tersimpan di dalam dosimetri tersebut. Elektron yang diserap fosfor dapat dikeluarkan dalam bentuk cahaya tampak. Intensitas cahaya yang dipancarkan dapat diukur dan sebanding dengan jumlah elektron yang terperangkap juga sebanding dengan energi radiasi yang diserap oleh material TL.

Besarnya dosis yang diterima dapat dihitung dengan menggunakan Persamaan (1)

$$
D=q F k
$$


Dimana $D$ adalah dosis radiasi yang diterima TLD (mGy), $q$ adalah muatan listrik (nC), $F k$ adalah faktor kalibrasi (mGy/nC).

Dengan mengunakan sistem komputerisasi yang mampu mengubah sistem analog menjadi data digital, dan data digital berubah menjadi sinyal-sinyal yang ditangkap oleh Photo Multiplier Tube (PMT) kemudian intensitas cahaya diperkuat dan diubah menjadi sinyal elektrik yang dikonversi ke dalam data digital Analog Digital Converter (ADC). Pada CR proses pengumpulan, pengolahan, penampilan, dan penyimpanan citra radiografi menggunakan imaging plate (stimulable phospor ${ }^{[3]}$. Bentuk format citra yang dihasilkan oleh $\mathrm{CR}$ ini adalah dalam bentuk DICOM (Digital Imaging and Communcation in Medicine).

Exposure index (EI) adalah parameter yang biasa digunakan untuk mengevaluasi jumlah paparan radiasi pada imaging plate. Nilai EI direkomendasikan untuk menghasilkan citra yang optimal. Konsep EI dirumuskan sejalan dengan speed class (film speed) dalam radiografi konvesional. Sistem CR agfa menyatakan nilai EI dalam bentuk indeks dosis yang disebut lgM (log median) / The Logarihm of The Median Exposure Value, yaitu nilai logaritma dari nilai median paparan di daerah ROI (region of interest) histogram. Sebagai contoh berdasarkan ISO 9236 - 1, film screen dengan speed class 400 membutuhkan rata - rata dosis detector 2,5 $\mu \mathrm{Gy}$ untuk menghasilkan citra yang bagus. Dengan demikian, sistem CR akan dibuat sesuai dengan konsep speed class 400 agar dosis dipusat detektor sekitar 2,5 $\mu \mathrm{Gy}$. Hubungan antara $\operatorname{lgM}$, dosis terukur, dan speed class dirumuskan dengan persamaan dibawah.

$$
\lg M=1,9607+\log \left[\frac{\mathrm{dose}(\mu \mathrm{Gy})}{2,5}\right]+\log \left[\frac{\text { speed class }}{400}\right]
$$

Atau

$$
\lg M=\log (E I)
$$

Faktor eksposi yaitu faktor yang mempengaruhi dan menentukan kualitas dan kuantitas dari penyinaran radiasi sinar- $X$ yang diperlukan dalam pembuatan citra radiografi.

Diagnostic Reference Level (DRL) Berbeda dengan batasan dosis pekerja radiasi dan publik yang merupakan keharusan, DRL lebih bersifat anjuran atau advisory. DRL merupakan batasan dosis (benchmark) bukan batasan range dosis minimal-maksimal. Nilai DRL yang direkomendasikan oleh IAEA diadopsi oleh Indonesia dengan nama tingkat panduan dosis radiodiagnostik melalui Surat Keputusan Kepala BAPETEN No01-P/Ka.BAPETEN/I-03 seperti table di bawah ini.

TABEL 1. Tingkat panduan dosis radiodiagnostik orang dewasa

\begin{tabular}{|l|l|l|}
\hline Pemeriksaan & \multicolumn{2}{|c|}{$\begin{array}{c}\text { Entrance Surface } \\
\text { Dose (mGy) }\end{array}$} \\
\hline $\begin{array}{l}\text { Lumbar } \\
\text { spine }\end{array}$ & AP & 10 \\
\hline & LAT & 30 \\
\hline & LSJ & 40 \\
\hline Abdomen & AP & 10 \\
\hline Pelvis & AP & 10 \\
\hline Hip Joint & AP & 10 \\
\hline Chest & PA & 0,4 \\
\hline & LAT & 1,5 \\
\hline $\begin{array}{l}\text { Thoracic } \\
\text { Spine }\end{array}$ & AP & 7 \\
\hline & LAT & 20 \\
\hline Dental & PERIAPICAL & 7 \\
\hline & AP & 5 \\
\hline Skull & AP & 5 \\
\hline & LAT & 3 \\
\hline & LAT & 20 \\
\hline
\end{tabular}

Keterangan: $P A$ : proyeksi posterior anterior, $L A T$ : proyeksi lateral, $L S J$ : proyeksi lumbosacraljoint, $A P$ : proyeksi anterior poaterior.

$D R L$ harus relevan dengan kondisi lokal, misalnya sebuah daerah atau negara di mana DRL tersebut diterapkan. Agar relevan, DRL ditentukan dari data survei dosis radiasi di banyak rumah sakit dalam suatu daerah atau negara tertentu. DRL harus dianggap sebagai parameter 
yang dinamis dan selalu diperbaharui sehingga survei dosis radiasi semestinya dilakukan secara rutin oleh rumah sakit setidaknya 3-5 kali dalam satu tahun [7].

ImageJ adalah software pengolah gambar berbasis open source dengan platform Java yang dikembangkan oleh Wayne Rasband dan tim di National Institute of Health (NIH). ImageJ mampu melakukan manipulasi kontras citra, filtering, menghitung area dan nilai piksel dari suatu ROI. ImageJ dapat menampilkan histogram dan profil dari citra yang dianalis [8].

\section{METODE DAN BAHAN}

Alat dan Bahan yang di perlukan adalah pesawat sinar-X dengan kondisi maksimum $150 \mathrm{kV}$ dan 400 mAs, TLD-100 LiF beserta TLD reader harshaw 3500, Obyek phantom, Kaset, digitizer, dan Image console CR Agfa.

Pengukuran Entrance Surface Dose (ESD) dilakukan dengan meletakkan 3 (tiga) Thermoluminescent detector (TLD) pada pusat lapangan radiasi (Center Point) dengan faktor eksposi seperti berikut.

TABEL 2. Faktor Eksposi untuk Pengukuran ESDTLD

\begin{tabular}{|c|c|c|c|}
\hline \multirow[t]{2}{*}{$\begin{array}{l}\text { Jenis } \\
\text { Pemeriksaan }\end{array}$} & \multicolumn{2}{|c|}{$\begin{array}{l}\text { Parameter } \\
\text { Eksposi }\end{array}$} & \multirow[t]{2}{*}{$\begin{array}{l}\text { FFD } \\
(\mathrm{cm})\end{array}$} \\
\hline & $\mathrm{kVp}$ & $\mathrm{mAs}$ & \\
\hline \multirow[t]{10}{*}{ Thorax PA } & 50 & 8 & \multirow[t]{10}{*}{120} \\
\hline & 50 & 10 & \\
\hline & 55 & 8 & \\
\hline & 55 & 10 & \\
\hline & 60 & 8 & \\
\hline & 60 & 10 & \\
\hline & 66 & 8 & \\
\hline & 66 & 10 & \\
\hline & 102 & 1 & \\
\hline & 102 & 2,5 & \\
\hline
\end{tabular}

Optimasi citra yang dimaksud adalah pada proses pembentukan citra yang didasarkan kepada nilai noise yang rendah berdasarkan hasil evaluasi citra phantom dengan nilai ESD yang tidak melebihi nilai DRL yang telah ditetapkan oleh Surat Keputusan Kepala BAPETEN No01$\mathrm{P} / \mathrm{Ka}$.BAPETEN/I-03. Evaluasi nilai noise pada citra dinilai dengan menggunakan software ImageJ. Hal ini dilakukan untuk melihat manakah yang memiliki noise terendah berdasarkan hasil dari penggunaan variasi faktor eksposi.

TABEL 3. Hasil Pengukuran nilai $\operatorname{lgM}$ (log median) dan ESDTLD Pemeriksaan thorax untuk setiap Variasi Eksposi

\begin{tabular}{|c|c|c|c|c|}
\hline \multirow{2}{*}{ No } & \multicolumn{2}{|c|}{$\begin{array}{c}\text { Parameter } \\
\text { eksposi }\end{array}$} & 1gM & $\begin{array}{c}\text { Dosis } \\
\text { (mGy }\end{array}$ \\
\cline { 2 - 4 } & $\mathrm{kVp}$ & $\mathrm{mAs}$ & & ) \\
\hline 1 & 50 & 8 & 1.75 & 0,083 \\
\hline 2 & 50 & 10 & 1.79 & 0,088 \\
\hline 3 & 55 & 8 & 1.91 & 0,098 \\
\hline 4 & 55 & 10 & 2.01 & 0,137 \\
\hline 5 & 60 & 8 & 2.06 & 0,113 \\
\hline 6 & 60 & 10 & 2.18 & 0,218 \\
\hline 7 & 66 & 8 & 2.29 & 0,222 \\
\hline 8 & 66 & 10 & 2.53 & 0,283 \\
\hline 9 & 102 & 1 & 2.08 & 0,114 \\
\hline 10 & 102 & 2,5 & 2.53 & 0,201 \\
\hline
\end{tabular}

Pengukuran ESD dilakukan dengan metode pengukuran langsung (direct method) menggunakan thermoluminesense dosimeter (TLD). Proses pengukuran ESD dilakukan dengan cara meletakkan 3 (tiga) Thermoluminescent detector (TLD) di pusat lapangan radiasi (Center Point) 
pada phantom thorax. Kemudian dilakukan 10 (sepuluh) kali ekspos pada phantom dengan 10 (sepuluh) kali variasi faktor eksposi dan masing-masing variasi faktor eksposi menggunakan TLD yang berbeda. Hasil perhitungan ESD dapat dilihat dalam Tabel 3.

Hasil yang didapatkan adalah dengan bertambahnya nilai eksposi yang digunakan maka nilai dosis yang diterima objek pun relatif bertambah. Optimasi citra yang dimaksud adalah jika faktor eksposi yang diberikan tidak mengurangi hasil pembentukan citra yang tampak.

Hasil penilaian citra didasarkan kepada nilai noise yang didapatkan. Citra yang baik adalah jika nilai noise rendah. Sedangkan evaluasi nilai noise diukur berdasarkan nilai piksel, untuk mengukur noise luas ROI (Region Of Interest) dianjurkan adalah 100 piksel ${ }^{[6]}$. Noise merupakan standar deviasi, apabila standar deviasi yang dihasilkan oleh citra tinggi maka nilai noise yang dihasilkan citra juga tinggi. Hasil pengukuran nilai standar deviasi pada penelitian ini akan ditunjukkan pada Tabel 4.

TABEL 4. Hasil pengukuran nilai standar deviasi citra thorax PA

\begin{tabular}{|c|c|c|c|}
\hline No & $\mathbf{k V p}$ & $\mathbf{m A s}$ & $\begin{array}{c}\text { Nilai Standar } \\
\text { Deviasi }\end{array}$ \\
\hline 1 & 50 & 8 & 10,281 \\
\hline 2 & 50 & 10 & 10,295 \\
\hline 3 & 55 & 8 & 6,605 \\
\hline 4 & 55 & 10 & 11,213 \\
\hline 5 & 60 & 8 & 7,559 \\
\hline 6 & 60 & 10 & 9,471 \\
\hline 7 & 66 & 8 & 6,138 \\
\hline 8 & 66 & 10 & 11,782 \\
\hline 9 & 102 & 1 & 5,645 \\
\hline 10 & 102 & 2,5 & 20,779 \\
\hline
\end{tabular}

Dari Tabel 4 terlihat bahwa nilai pengukuran standar deviasi cukup fluktuaktif. Nilai standar deviasi yang rendah didapatkan saat penggunaan faktor eksposi $55 \mathrm{kV}$ dan $8 \mathrm{mAs}$ serta $66 \mathrm{kV}$ dan $8 \mathrm{mAs}$ untuk teknik $\mathrm{kV}$ standar. Sedangkan untuk teknik kV tinggi nilai standar deviasi yang rendah saat penggunaan faktor eksposi $102 \mathrm{kv}$ dan $1 \mathrm{mAs}$. Seperti yang terlihat pada gambar 1.

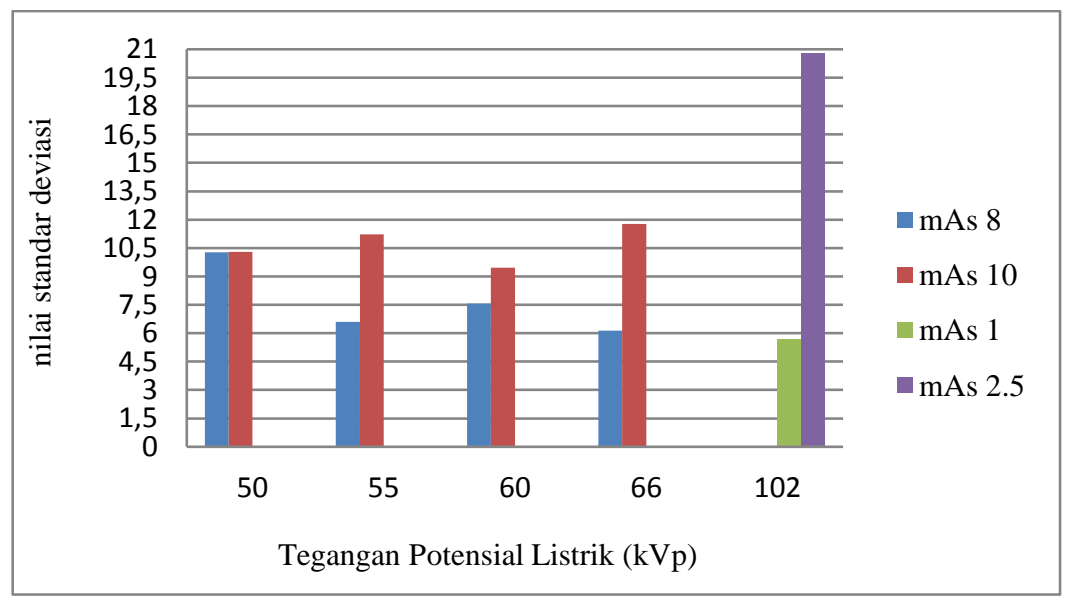

GAMBAR 1. Pengaruh kenaikan faktor eksposi terhadap nilai standar deviasi

\section{HASIL DAN PEMBAHASAN}

Faktor eksposi adalah faktor yang mempengaruhi dan menentukan kualitas dan kuantitas dari penyinaran radiasi sinar- $X$ yang diperlukan dalam pembuatan citra radiografi. Pada pemeriksaan thorax PA dalam penelitian ini, dilakukan pula dengan menerapkan teknik $\mathrm{kV}$ tinggi. Teknik kV 
tinggi merupakan teknik radiografi yang menggunakan faktor eksposi minimal $100 \mathrm{kV}$ sehingga perbedaan densitas antara tulang, jaringan lunak, dan udara relatif homogen. Teknik ini disebutkan bahwa dapat memberikan dosis yang lebih rendah kepada pasien. Pengambilan data menggunakan teknik $\mathrm{kV}$ tinggi dalam penelitian ini dikarenakan untuk melihat ESD yang didapatkan dan gambaran citra yang terbentuk, walaupun pada RS X teknik tidak diaplikasikan dalam keseharian. Tingginya nilai $\mathrm{kV}$ yang digunakan pada teknik ini diseimbangkan dengan penurunan nilai mAs.

Berdasarkan Tabel 1 diperlihatkan bahwa kenaikan faktor eksposi cenderung diikuti dengan kenaikan nilai $\mathrm{ESD}_{\mathrm{TLD}}$, baik untuk penggunaan $\mathrm{kV}$ standar maupun untuk penggunaan $\mathrm{kV}$ tinggi. Pada Tabel 1 terlihat bahwa nilai ESD terendah diperoleh saat penggunaan faktor eksposi yang terkecil yaitu pada penggunaan $50 \mathrm{kV}$ dan $8 \mathrm{mAs}$, pada penggunaan faktor eksposi ini diperoleh nilai ESD sebesar 0,083 mGy. Hasil pengukuran nilai $\lg$ ( $\log$ median) pun yang paling kecil ada pada kondisi faktor eksposi $50 \mathrm{kV}$ dan $8 \mathrm{mAs}$ namun bila dibandingkan dengan rentang yang diberikan oleh rekomendasi referensi yaitu 1,9-2,5 nilai ini berada di bawah rentang sehingga pada kondisi ini gambaran yang ditampilkan masih dibawah standar dan ini dibuktikan dengan penghitungan nilai standar deviasi yang didapatkan tinggi yaitu 10,281 seperti terlihat pada gambar 2 .

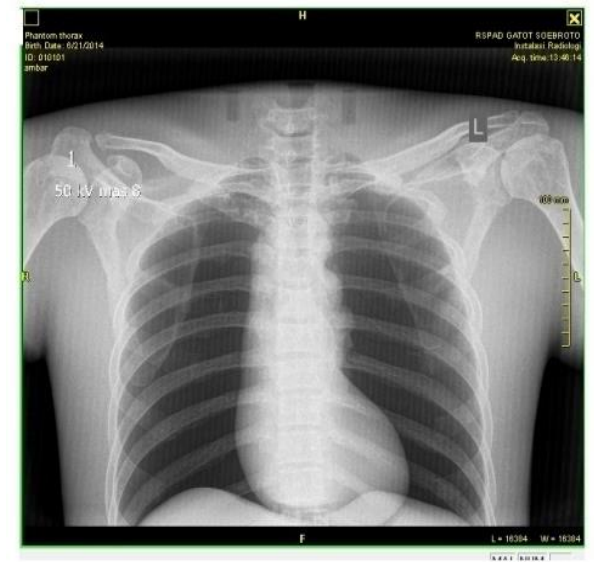

GAMBAR 2. Citra Radiografi Thorax PA kondisi eksposi $50 \mathrm{kV}$ dan $8 \mathrm{mAs}$

Hasil gambar citra radiografi terbaik bila dilihat berdasarkan pada nilai standar deviasi yang terendah dan nilai Entrance Surface Dose yang paling rendah adalah gambar citra ke tiga saat penggunaan faktor eksposi $55 \mathrm{kV}$ dan $8 \mathrm{mAs}$ memiliki nilai standar deviasi 6,605. Citra radiografi ditampilkan pada Gambar 3.

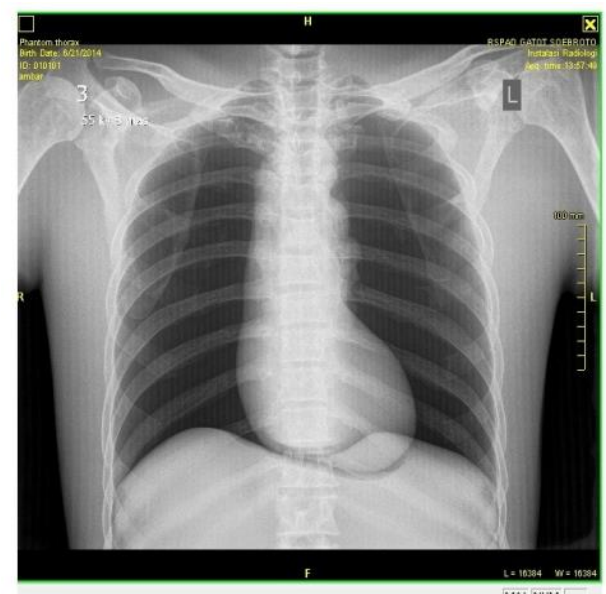

GAMBAR 3. Citra Radiografi Thorax PA kondisi eksposi $55 \mathrm{kV}$ dan 8 mAs

Untuk evaluasi citra gambar 3 diperoleh gambaran thorax terlihat simetris yang ditandai dengan posisi processus spinosus ditegah kedua clavicula. Gambaran paru-paru dan mediastinum juga 
terlihat baik, begitu juga dengan gambaran tulang belakang, scapula, jantung, aorta, trakhea, serta kedua sinus costoprenicus, serta gambaran proksimal bronkhus dapat terlihat. Gambar 3 merupakan gambar yang memiliki nilai standar deviasi terendah dan nilai dosis yang relatif rendah.

Dari kedua gambar yaitu gambar 2 dan gambar 3 memiliki keuntungan dan kerugian dilihat dengan berdasarkan nilai dosis, noise, dan kriteria gambarannya. Untuk nilai dosis terendah dimiliki oleh Gambar 2, untuk noise terendah, dosis optimum dan kriteria gambaran terbaik dimiliki oleh Gambar 3. Namun untuk penggunaan teknik kV tinggi terjadi saat faktor eksposi yang digunakan yaitu $102 \mathrm{kV}$ dan $1 \mathrm{mAs}$ dengan nilai standar deviasi sebesar 5,645 ditunjukkan pada gambar 4.

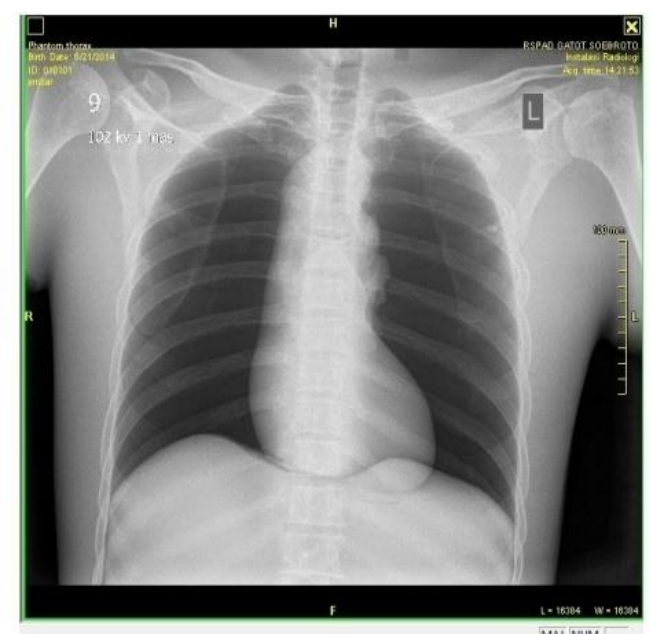

GAMBAR 4. Citra Radiografi Thorax PA kondisi eksposi $102 \mathrm{kV}$ dan $1 \mathrm{mAs}$

Evaluasi citra gambar 4 didapatkan gambaran thorax terlihat simetris yang ditandai dengan posisi processus spinosus ditegah kedua clavicula. Gambaran paru-paru dan mediastinum juga terlihat baik, begitu juga dengan gambaran tulang belakang, scapula, jantung, aorta, trakhea, serta kedua sinus costoprenicus. Dan gambaran proksimal bronkhus tervisualisasi dengan jelas. Berdasarkan uraian diatas maka dapat disimpulkan bahwa nilai piksel dapat digunakan untuk menentukan nilai noise dari suatu citra gambar digital. Nilai noise ini dipengaruhi oleh faktor eksposi yang digunakan. Referensi menyebutkan bahwa rekomendasi nilai $\operatorname{lgM}$ 1,8-2,5 untuk optimasi citra. Dan pada penelitian ini nilai lgM yang dihasilkan yaitu dalam rentang 1,75-2,53 untuk sepuluh kali ekspos.

Dengan melihat hasil secara keseluruhan dari hasil penelitian ini , kondisi eksposi optimum pemeriksaan thorax PA (dinyatakan dengan nilai $\operatorname{lgM}$ ) terjadi ketika penggunaan faktor eksposi $55 \mathrm{kV}$ dan $8 \mathrm{mAs}$ karena nilai $\operatorname{lgM}$ yang didapat yaitu 1,91 nilai standar deviasi 6,605 serta nilai ESD sebesar 0,098 mGy. Saat kondisi eksposi ini nilai ESD yang didapatkan lebih rendah jika dibandingkan dengan nilai DRL untuk pemeriksaan thorax yaitu 0,4 mGy [13], sedangkan untuk kualitas citra pada kondisi inilah hasil pengukuran nilai standar deviasi yang didapatkan rendah. Untuk kriteria gambaran pada kondisi cukup banyak yang terlihat sehingga dapat menampilkan gambaran yang dibutuhkan untuk mengakkan diagnosa.

Berdasarkan pembahasan yang telah dijelaskan diatas penelitian ini dilakukan karena untuk mencari citra radiografi terbaik yang dapat menampilkan gambaran organ-organ dengan jelas sehingga dapat membantu dalam menegakkan diagnosa dengan tepat tetapi tetap memperhatikan dosis yang diterima oleh pasien dengan tetap mengikuti perkembangan teknologi radiografi yang semakin canggih yaitu menggunakan Computed Radiography (CR). Pada prinsipnya pemeriksaan ditujukan agar pasien mendapatkan manfaat langsung sehingga pemberian dosis tidak dibatasi akan tetapi tetap memperhatikan keselamatan pasien. Jika dosis yang diberikan secara konsisten dibawah Diagnostic Reference Level (DRL) yang telah ditetapkan dan menjadi acuan, maka hal ini menandakan telah dilakukan optimasi yang baik dalam memberikan jaminan keselamatan pasien. 


\section{KESIMPULAN}

Dari hasil penelitian yang telah didapatkan maka dapat ditarik kesimpulan bahwa Optimasi dapat dicapai dengan kompromi antara dosis yang diterima pasien dengan kualitas citra gambar yang ditunjukkan oleh rendahnya nilai noise citra gambar. Optimasi pada pemeriksan thorax PA terjadi pada ESD 0,098 mGy yaitu saat penggunaan kondisi eksposi $55 \mathrm{KV}$ dan $8 \mathrm{mAs}$ dengan nilai noise 6,605. Sedangkan untuk teknik KV tinggi menggunakan $102 \mathrm{KV}$, optimasi terjadi dengan nilai ESD 0,114 mGy. Nilai ESD yang didapatkan 0,098 mGy lebih rendah jika dibandingkan dengan nilai DRL untuk pemeriksaan thorax yaitu 0,4 mGy[13]. Penelitian ini menghasilkan rentang nilai $\operatorname{lgM}$ (log median) optimum 1,75-2,53 dan untuk teknik $\mathrm{kV}$ tinggi 2,53 .

\section{REFERENSI}

[1] IAEA. (2007).Technical Report Series No. 457 Dosimetry in Diagnostic Radiology: an International Code of Practic. Austria:IAEA Vienna.

[2] Akhadi, M. (2000). Dasar-Dasar Proteksi Radiasi Edisi I. Jakarta: Rineka Cipta.

[3] Ballinger.W.Philip, Eugene.D.Frank. (2003). Merrills Atlas of Radiographic Positions Volume 2 10th Edition. Mosby.

[4] American Association of Physicists in Medicine. (2009) . Report No.116, Task Group 116: An Exposure Idicator For Digital Radiography. USA : One Physics, College Park, MD.

[5] Bushberg JT, Seibert JA, Leidholdt EM, Boone JM. The Essential Physics of Medical Imaging. 2nd ed. Philadelphia, Pa: Lippincott Williams \& Wilkins, 2002.

[6] Bushong, S. C. (2000). Radiologic science for technologist. St. Louis: CV. Mosby Company.

[7] Seeram, Euclid, Brennan, Patrick, C. Diagnostic reference levels in radiology. Radiologic Technology. May-June, 2006.

[8] ImageJ User Guide http://rsb.info.nih.gov/ij/

[9] Philips Bucky Diagnost X-Ray Unit .2014.

[10] www.terraaster.ro/nou/images/stories/philips_bucky_diagnost.jpg diakses pada tanggal 05 Juni 2014 pukul 06.06 WIB

[11] Datasheet CR 35 X Digitizer. 2009. Agfa Healthcare NV. Belgium. www.agfahealthcare.com

[12] Datasheet CR MD 4.0 General Cassette. 2009. Agfa Healthcare NV. Belgium. www.agfahealthcare.com

[13] TLD Reader.2014.

[14] www.thermoscientific.com/en/product/harshaw-tld-model-3500-manualreaders1.htm diakses pada tanggal 09 Juli 2014 pukul 19.43 WIB

[13] Ridwan, M. (2003). Keputusan Kepala BAPETEN No.01-P/Ka-BAPETEN/I- 03 Tentang Pedoman Dosis Pasien Radiodiagnostik. Jakarta: Bapeten. 